\title{
RISK MANAGEMENT OF MAGNETIC FIELD FROM INDUSTRIAL INDUCTION HEATER - A CASE STUDY
}

\author{
Tarmo Koppel ${ }^{1}$, Inese Vilcane ${ }^{2}$, Piia Tint ${ }^{1}$ \\ ${ }^{1}$ Tallinn University of Technology, Estonia; ${ }^{2}$ Riga Technical University, Latvia \\ tarmo.koppel@ttu.ee; inese.vilcane@rtu.lv
}

\begin{abstract}
In the study an industrial occupational setting was investigated in order to determine the workers exposure to the magnetic fields from induction ovens and to develop risk mitigation procedures to lower the exposure. Electromagnetic field measurements were conducted and the workers exposure to the electromagnetic fields was assessed in the framework of the new occupational electromagnetic field legislation. The results show that the exposure could be significantly reduced by implementing relatively easy mitigation measures, including workplace rearrangement, work procedure redesign etc. Time-weighted average exposure to the magnetic field could be lowered from $2.57 \mu \mathrm{T}$ (maximum observed procedure case) to $0.12 \mu \mathrm{T}$ (recommended procedure scenario after interventions). The investigation also revealed that little attention is paid to training the workers who may be affected by high levels of electromagnetic fields. Considering the requirements of the new European Union and national electromagnetic field legislation, immediate planning of appropriate schooling programs is necessary for all parties involved: employers, workers, work environment specialists.
\end{abstract}

Keywords: induction, heater, oven, intermediate frequency, electromagnetic fields, occupational exposure, work, risk management.

\section{Introduction}

In this study an industrial occupational setting was investigated in order to measure and determine the workers exposure to the magnetic fields (MFs) from an industrial induction heater. Nowadays induction heating is commonly used in the metal-forming industries for welding, annealing, hardening and brazing [1].

The industrial settings may include a variety of electrical instruments and appliances, hence providing countless variations of electromagnetic fields' exposure scenarios. Even if several workstations utilize the equipment of the same make and model, often the layout of the workstation, and peripheral devices may render the risk assessment inadequate based on the equipment alone.

In an ideal laboratory conditions, multiple units of the same equipment of the same make and model may indeed propagate electromagnetic fields (EMFs) with the same characteristics. The characteristics of the radiated EMF include the geometrical radiation pattern, amplitude, mixture of frequencies, waveform etc. Whereas the actual industrial environment is hardly a laboratory setting where other sources are dismissed and the surrounding objects including the building structure and the materials affect the propagation of the electromagnetic wave. In practice, it is important to measure the exposure of workers to the electromagnetic fields in actual work settings, as risk assessment by numerical calculations, simulations or by devices' documentation would leave much room for error and may put workers in risk.

Today, European companies are expected to be in compliance with the new legislation on occupational exposure to the electromagnetic fields. Corresponding EU directive was issued in 2013 and was to be implemented into the national legislation of member states by 2016 July $1^{\text {st }}[2 ; 3]$.

The legislation is a set of rules, which the employer needs to fulfill, but as with any other legislative document, the rules are general and not scenario or case specific. Induction heating systems are a specific type of industrial appliances that generate high level intermediate frequency electromagnetic fields. Some appliances generate EMFs as a byproduct, but in case of induction heating, the magnetic field is intentional in order to heat up the metal or other electrically conductive objects.

The induction heaters preceded the development of the microwave heating applications. The production of heat by induced currents was recognized already in the early 1880s. First practical induction heaters with the frequencies above the power frequencies were built in the period between the two World Wars [4; 5].

Nowadays, induction heaters operate at frequencies from power frequency to several tens of $\mathrm{MHz}$. Magnetic fields from lower frequency induction heaters are capable of penetrating and heating the 
material more deeply, but are also accompanied by stronger magnetic fields as compared to higher frequency units. The strongest magnetic fields are generated by induction heaters operating below $10 \mathrm{kHz}$ [6-8]. Both electric and magnetic fields are generated by the induction heaters. Mantiply et al. investigated and concluded electric fields from $2 \mathrm{~V} \cdot \mathrm{m}^{-1}$ to $8.2 \mathrm{kV} \cdot \mathrm{m}^{-1}$ and magnetic fields from 0.1 to $21 \mathrm{~A} \cdot \mathrm{m}^{-1}$ (i.e. 0.12 to $26.4 \mu \mathrm{T}$ ) [8]. Decat et al. (2006) investigated induction heater systems and determined a great variation in the operating time, operator's distance to the unit and exposure to magnetic field ( $20 \mu \mathrm{T}$ to $0.31 \mathrm{mT})$ [9].

The magnetic field from the induction heater system is mainly emitted by the coil applicator [10].

With respect to production management, other traditional industrial heating methods (electrical heating, gas heating) have several shortcomings as compared to induction heating. The main advantages are: creating intense heat very quickly and in well-defined locations. This results in shorter process time with reliable quality. Also, induction heating is more energy efficient. The shorter startup and shutdown times lower workers cost [11]. The induction heating has also improved industrial processes as the consistency and repeatability of the heating process improves the quality and increases the productivity; it is a contactless heating process where the target is not affected by being in contact to the heating element [12]. The induction heating is also seen to be more clean and safe as the magnetic field heats directly the target, whereas the temperature of the surrounding area is lower, also avoiding surrounding materials [12].

Workers safety from induction heaters has become more relevant due to recent technological developments and emergence of high temperature superconductor (HTS) based induction heaters. Loss free conduction of current and the HTS capability of carrying high current densities in the temperatures $20-80 \mathrm{~K}$ are new features compared to the conventional technology [13].

As induction heater operators and any other personnel coming to close range of this system may be exposed to high magnetic fields, these fields need to be measured and the safety of workers assessed in the framework of the relevant national legislation. The aim of this study is to characterize by an example of a typical induction heater unit the magnetic field exposure scenarios and the ways of its mitigation; a variety of options that can be used to reduce the workers exposure are analyzed.

\section{Materials and methods}

The subject of this investigation is the induction heater system that is used in production to melt aluminum in otherwise iron containing units. Electromagnetic field measurements were done and the workers exposure to the electromagnetic fields was assessed in the framework of the new occupational electromagnetic field legislation.

Measurements of the electromagnetic fields were conducted across the working area where the induction heater was positioned. The measurements were done by three means.

1. Spatial measurements. Spatial measurements of the resultant field, based on the grid pattern were conducted. The grid was marked on the floor by $0.5 \mathrm{~m}$ steps. The field intensity map was drawn based on the spatial field intensity data. The grid measurement data were also used later to calculate the workers exposure in time series, over several working procedures. The measurements were taken at the height of $1 \mathrm{~m}$, which is the central height of the induction heater coil.

2. Spectrum measurements. The spectrum of the induction heater generated field was determined by spectrum analyzer measurements. The spectrum measurements were done in time series. The spectrum measurements provide information on the dynamics of the amplitude and the frequency of the induction heater unit. The spectrum analyzer was at the height of $0.7 \mathrm{~m}$ (induction heater work bench level) and at a distance of $0.6 \mathrm{~m}$ from the induction heater coil.

3. Exposimetry measurements. Personal exposure measurements provided understanding on the actual exposure of the worker. The worker was equipped with the exposimeter in the front abdominal area (at the height of the induction heater coil). The exposimeter logged the resultant field exposure at the worker's position for several consecutive working procedures, demonstrating different work activities encountered during the same process.

Visual observations of the worker's movements were conducted to determine the path of the worker during work procedures. The movements were drawn on the work area plan and spatial 
analysis was conducted to assess the exposure over the time of the procedures. By videorecordings, the time was measured the worker spends at any of the locations (grid points) at the workstation. The recordings were analyzed in the personal computer using video player software, where accumulating seconds were counted based on the video player timer. The data allowed the assessment of time weighted average exposure of the worker, based on the field intensity map determined earlier.

Also, the visual observations granted the insight to the activities of the worker during the heating process. These activities are directly related to the heating process, but also secondary activities involved with other workers or preparing to the coming tasks were observed.

Workers were questioned about the working methods and the necessity of any of the observed tasks. The questioning also provided information about the companies work arrangement and safety procedures related to the work with induction heaters.

The practical challenge in making measurements at the induction heater worksite is to do with the alternating power level of the induction heater. Consequently, the magnetic field is also changing in time, having stabilized on the maximum level for the brief period at the middle of the heating procedure.

\section{Exposure assessment}

Exposure to magnetic field was estimated by time-weighted average $\left(B_{T W A}\right)$, in microTeslas $(\mu \mathrm{T})$ as presented in formula 1 . In assessing the time weighted average, the exposure was accounted only when the induction system was active, i.e. activities prior to switching the induction heater system on and after switching it off accounted for null exposure from the induction heater system. Timeweighted average is accounting each time period the worker spends in locations where procedure specific tasks are performed $\left\{t_{1}, t_{2}, \ldots, t_{n}\right\}$ complemented by the exposure to the magnetic field (magnetic flux density, $B$-field) $\left\{B_{1}, B_{2}, \ldots, B_{n}\right\}$ at the corresponding locations.

$$
B_{T W A}=\frac{\sum_{i=1}^{n} t_{i} B_{i}}{\sum_{i=1}^{n} t_{i}}(\mu \mathrm{T}) .
$$

In case of measurement devices with a fixed sampling time, the time-weighted average equals the arithmetic means of the measurements [14]. In this study, the latter applies to the exposimeter measurements, which use a predetermined sampling rate.

The exposure during a single work procedure was also assessed by a cumulative exposure index $\left(B_{\text {cum }}\right)$, expressed in microTesla-seconds $(\mu \mathrm{T}-\mathrm{sec})$. Cumulative exposure for each procedure was obtained by adding up workplace specific exposures $\left\{B_{1}, B_{2}, \ldots, B_{n}\right\}$ measured/calculated by one second increments (formula 2) according to the start and end of the work procedure obtained from visual observation records and magnetic field spatial measurements. The cumulative exposure indicator is different from the time-weighted average, since it better characterizes single work procedure accumulated exposure (dosage), since no time averaging is performed. Work procedures differ from each other by the length of time spent on any of the activities resulting in a variation of total work procedure time. In case, more time is spent at the vicinity of the induction heater, and accounting the excess time needed sometimes to complete the task, the summed total exposure is also increased.

$$
B_{\text {cum }}=\sum_{i=1}^{n} B_{i}(\mu \mathrm{T}-\mathrm{sec})
$$

Based on five consecutive procedures of accumulated exposures, an average exposure was calculated, which characterizes the typical procedure scenario. Exposimeter based measurements were used to calculate means, medians, minimum and maximum values in $\mu \mathrm{T}$ for all measured frequency bands and for total exposure.

\section{Electromagnetic field meters}

The meter used for worker's personal exposure measurements and spatial exposure measurements was Gigahertz Solutions NFA400 (Langenzenn, Germany). The meter is capable of simultaneous measurements of 6 frequency bands: 1) $16.7 \mathrm{~Hz}$, 2) $50 \mathrm{~Hz}$, 3) $100 \mathrm{~Hz}$, 4) $150 \mathrm{~Hz}, 5$ ) <2 kHz excluding the fore mentioned, 6) $>2 \mathrm{kHz}$. The frequency range: $5 \mathrm{~Hz}$ to $400 \mathrm{kHz}$. Measurement range for 
magnetic flux density 1 nanoTesla $(\mathrm{nT})$ to 20 microTesla $(\mu \mathrm{T})$ and for electrical field strength 0.1 $1999 \mathrm{~V} \cdot \mathrm{m}^{-1}$.Either the magnetic and electric field could be measured by the meter. For magnetic field, the meter is a three-axial meter, capable of measuring all three axes separately and calculating the resultant field. The measurements were taken in tRMS (true Root Mean Square) mode. In worker's personal exposure logging 3D magnetic field was measured at a sampling rate of $0.1 \mathrm{sec}$.

Spectrum measurements were conducted with a spectrum analyzer AaroniaSpectran NF5035 (Strickscheid, Germany). The spectrum analyzer has an integrated 3D (isotropic) magnetic sensor, with a measuring range of 1 picoTesla $(\mathrm{pT})$ to 2 milliTesla $(\mathrm{mT})$. The unit is capable also of electric field measurements of $0.1 \mathrm{~V} \cdot \mathrm{m}^{-1}$ to $20 \mathrm{kV} \cdot \mathrm{m}^{-1}$. The frequency range is $1 \mathrm{~Hz}$ to $1 \mathrm{MHz}$. The measurements were taken in RMS mode. The spectrum analyzer was used in conjunction with the laptop computer, which recorded the spectrum at the induction heater in time series.

All the measuring instruments were calibrated.

In the following chapters the measured and visually observed procedures are analyzed. A simulation is performed to recommend an alternative procedure in order to reduce the worker's exposure to the magnetic field. The simulation is based on the field intensity map, i.e. the same data as the exposure in actual conditions.

This study does not address the electromagnetic fields' induced limb currents in the human body.

\section{Results and discussion}

The object of the investigation was an induction heating system consisting of the induction heater coil, high current cables and the control unit. The system is complemented by the cooling system, whereas the induction heater coil and the current feeding cables carry a coolant flow to prevent excess heating of the system. The induction heater system was capable of $60 \mathrm{~kW}$ maximum power, but it was used at $20 \mathrm{~kW}$ due to the production tasks assigned to that heater system; maximum power was never used on that unit. As the strength of the magnetic field depends on the power of the system, i.e. the level of current passing through the cables and the coil, the results characterize the exposure scenarios at the above mentioned typical power level, which is representative exposure to workers of the investigated work station. Figure 1 gives a perspective of the investigated system, whereas red areas designate the magnetic field or its source. The induction heater system generates intermediate frequency high current that is directed by the water-cooled cables to the heater coil. The tense magnetic field emitted by the coil heats up the metallic article placed within the coil. The heating process is regulated by the amount of current fed into the coil and/or the time. The control unit is regulating the current by raising or lowering the voltage. When there is more metal that needs to be heated up, higher currents are fed to the coil, resulting up to 200 Amperes (A) for the investigated unit.

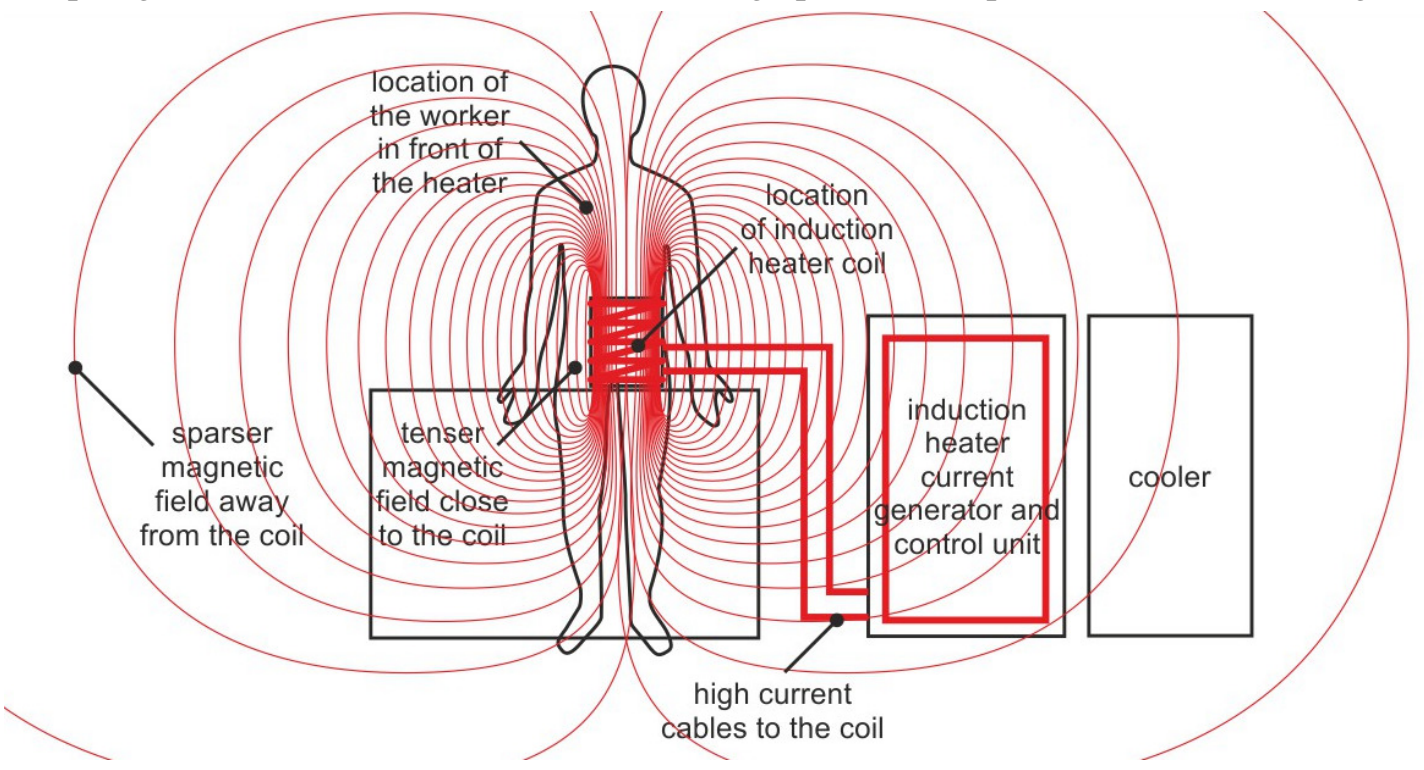

Fig. 1. Perspective view of the induction heater system work station; magnetic field or its sources are marked in red 
The vertical special distribution of the magnetic field in front of the induction heater coil (Figure 2) indicates the amplitude of the field and is most prominent on the work bench height $(0.7 \mathrm{~m})$. Although the central axis of the coil is at $0.9 \mathrm{~m}$, it is likely that the work bench made of iron perturbs the field and is focusing it at the worker's position somewhat lower. $0.7 \mathrm{~m}$ height is however the height of the reproductive organs, hence posing a possible health risk.

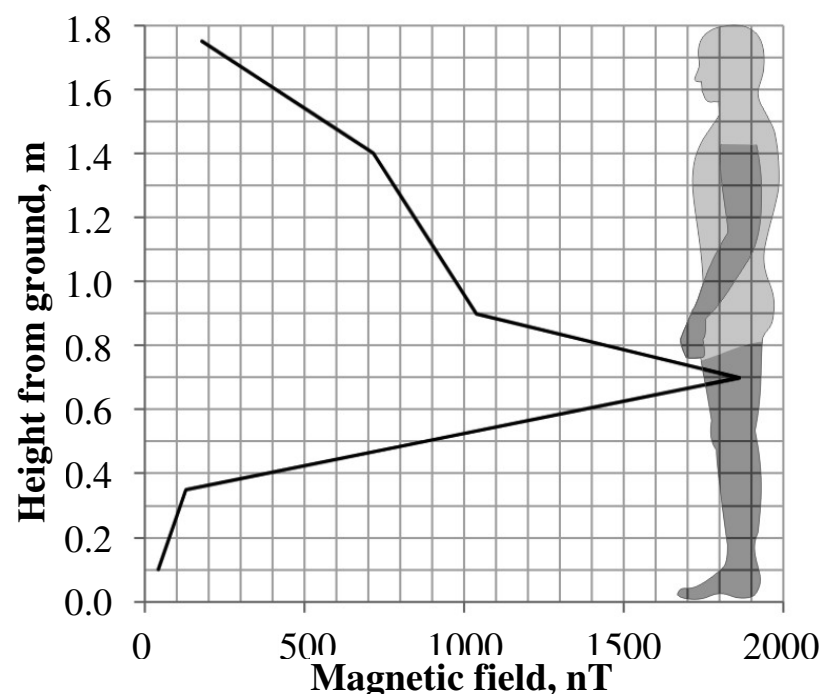

Fig. 2. Magnetic field vertical spatial distribution in front of the induction heater coil; measurement height corresponds to: $0.1 \mathrm{~m}$ and $0.3 \mathrm{~m}$-feet level; $0.7 \mathrm{~m}$ - work bench level; $0.9 \mathrm{~m}$ - induction coil central height; 1.4 - chest, heart level; $1.75 \mathrm{~m}$ - head level

Strong magnetic field is focused in the immediate vicinity of the induction heating system (Figure 3). All the main components of the system: 1) the induction coil, 2) cables carrying the current and 3) the current generator control unit are the significant sources.

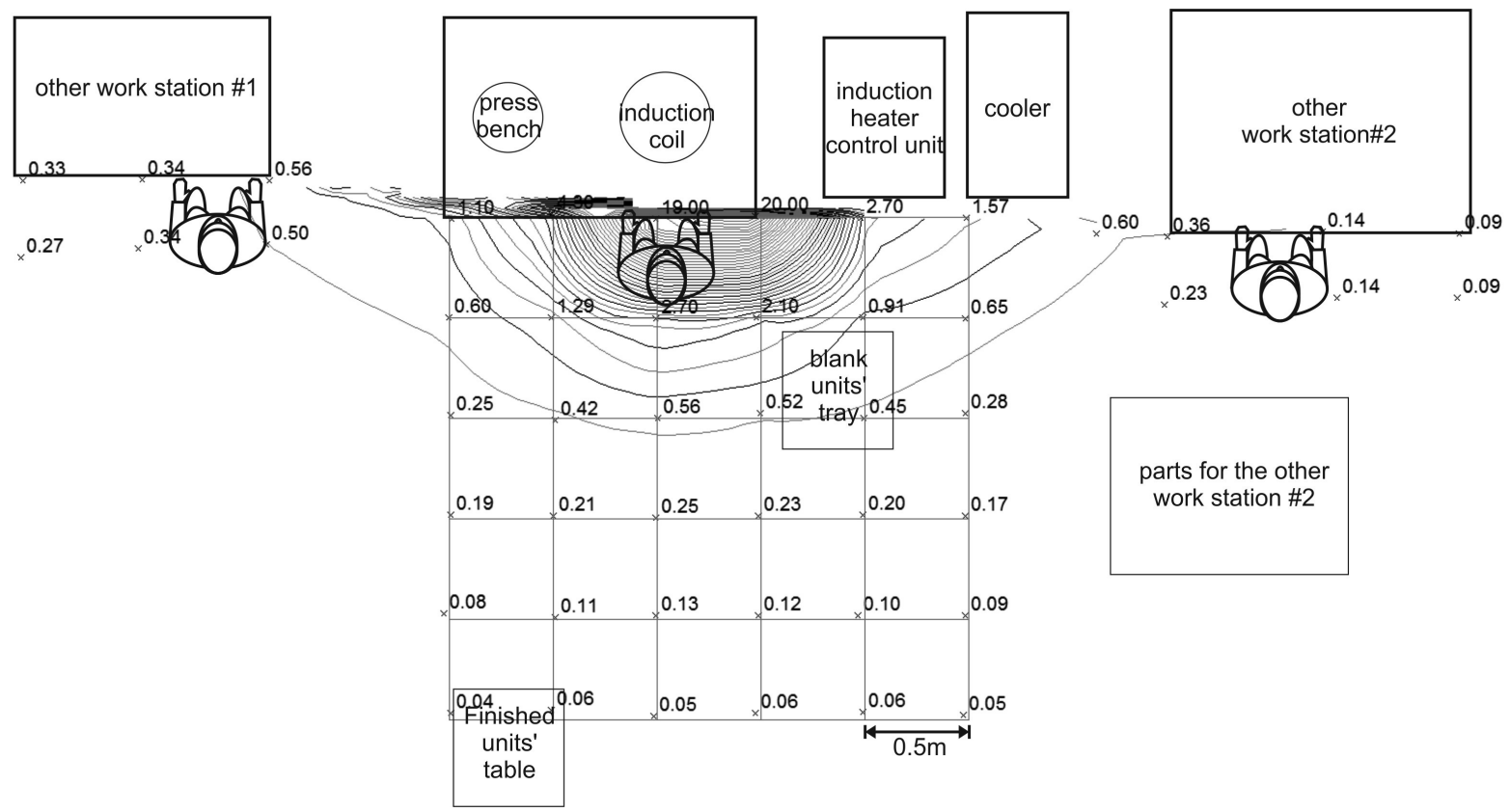

Fig. 3. Magnetic field spatial distribution (in microTeslas) from the induction heater and the general layout of the work area: induction heater work station in the middle, one other work station to the left (\#1) and one to the right (\#2)

Based on the visual observation of working procedures using the induction heater (Figure 5), the nominal work procedure was identified as follows (the movement of the worker is marked with a thick line, whereas the numbered points represent an activity at the corresponding location) (Figure 4): 
1. Taking the blank unit from the blank units' tray.

2. Placing the unit under the induction heater table and closing the heater coil on the unit.

3. Switching the heater on from the control unit.

4. Preparing the auxiliary unit to be inserted into the unit in the press bench.

5. Waiting for the heater to complete.

6. Removing the unit, after the heater has automatically switched off.

7. Pressing the unit.

8. Moving the processed unit to the finished units table.

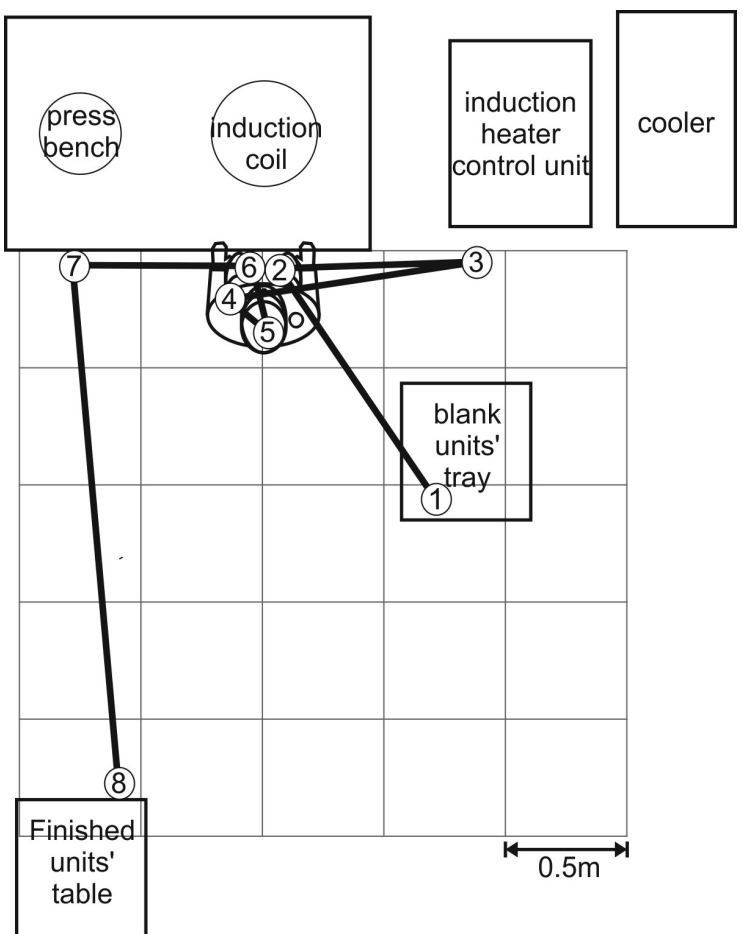

Fig. 4. Movements of the worker in a nominal work procedure (for activity number see the list below)

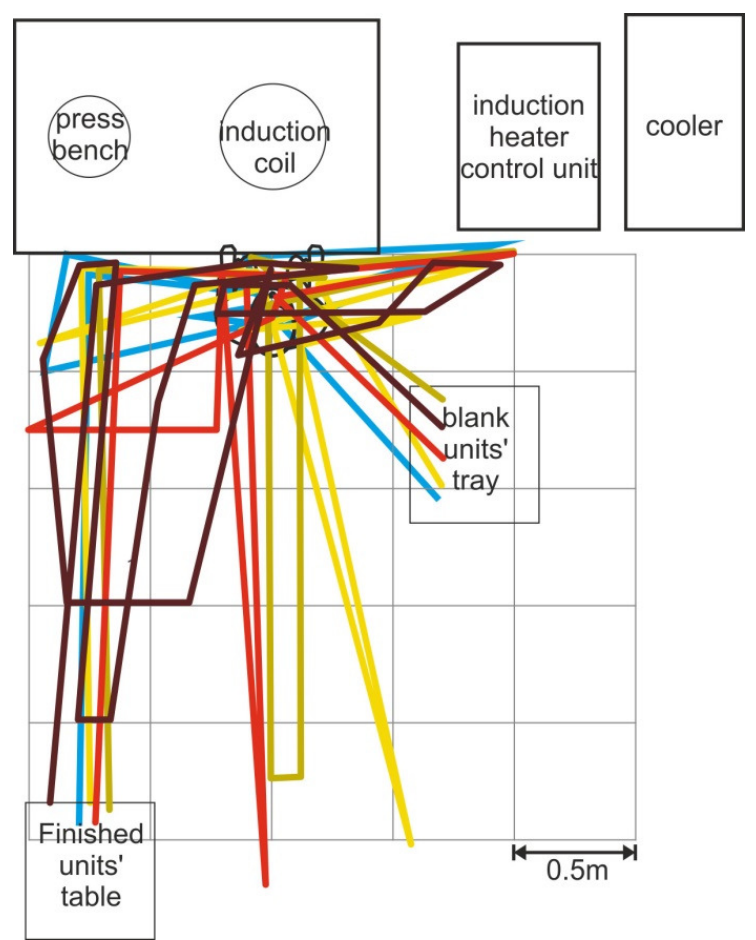

Fig. 5. Actual movements of the worker in consecutive work procedures; separate colours represent different consecutive procedure rounds

In the nominal work procedure only the necessary activities are undertaken, i.e. the worker has not left the workstation to go to some other location to wait the ending of the induction heating procedure - the worker remains to wait in front of the induction heater unit. Therefore, the nominal working procedure also describes the worst case exposure scenario under the current work machinery setup and work procedure arrangement.

The nominal procedure represented the typical tasks required to fulfil the work task. However, in many cases the nominal work procedure is deviated by 1) doing secondary tasks with the induction heater, 2) interacting with other workers, 3) changing the place for waiting. Waiting in other locations and interacting or collaborating with other workers take the worker further away from the induction heater, hence also reducing the exposure. Doing technical adjustments on the induction heater system however places the worker's vital body regions (head, torso) closer to the magnetic field source.

Based on the visual observations and interviews with the staff, several high exposure circumstances were identified, many of which could be avoided. Table 1 presents an overview of such scenarios.

In examining the field distribution, we see the magnetic field decreasing at exponential rate and achieving relatively negligent levels at 3-5 m distance. The recommended intervention scenario is simulated based on the field distribution map. Several intervention methods are applied to reduce the induction heater operator's exposure to the excess electromagnetic fields. Minimal exposure policy is followed. 
High magnetic field exposure circumstances at the induction heating work area

\begin{tabular}{|c|c|c|}
\hline $\mathrm{Nr}$ & Case & High exposure circumstances \\
\hline 1 & $\begin{array}{l}\text { Control unit placed too } \\
\text { close to the induction } \\
\text { heater }\end{array}$ & $\begin{array}{l}\text { The induction heater system's control unit was placed right } \\
\text { next to the induction heater coil. This work layout forces the } \\
\text { operator to bare the exposure to the magnetic field in any } \\
\text { pattern of movements during the process, as the heating } \\
\text { process must be initiated manually from the control unit. }\end{array}$ \\
\hline 2 & $\begin{array}{l}\text { Operator waiting too } \\
\text { close to the heater }\end{array}$ & $\begin{array}{l}\text { During the induction heating process the operator was waiting } \\
\text { right at the induction heating bench for the heating to end, } \\
\text { hence being exposed to excess levels of magnetic field. }\end{array}$ \\
\hline 3 & $\begin{array}{l}\text { Exposing vital body } \\
\text { regions while doing } \\
\text { adjustments }\end{array}$ & $\begin{array}{l}\text { During some procedures, the worker was adjusting the heater } \\
\text { station benches mechanisms or doing maintenance, while the } \\
\text { heater element was active. By doing so, the worker's head was } \\
\text { positioned to } 0.55 \text { m distance from the heater element, causing } \\
\text { a significant exposure to the head. }\end{array}$ \\
\hline 4 & $\begin{array}{l}\text { Interaction with other } \\
\text { workers }\end{array}$ & $\begin{array}{l}\text { During the operation of the induction heater, other workers } \\
\text { came to interact with the operator in the vicinity of the heater. } \\
\text { Such interactions included delivering blank units, fetching } \\
\text { ready-made units, coordinating about production processes etc. } \\
\text { Being close to the active induction heater exposed these } \\
\text { workers and the operator of the induction system to excessive } \\
\text { magnetic field. }\end{array}$ \\
\hline 5 & $\begin{array}{l}\text { Metal objects focus the } \\
\text { magnetic field }\end{array}$ & $\begin{array}{l}\text { The heightened exposure was also seen to happen because of } \\
\text { metals in the work area. The induction heater bench, being } \\
\text { made of iron, focused magnetic field around its edges; the } \\
\text { operator's reproductive organs area was in contact with the } \\
\text { metal hence exposing these organs to heightened field. Other } \\
\text { metal objects that the person is carrying (glasses, zippers etc.) } \\
\text { should also be accounted for. }\end{array}$ \\
\hline 6 & Adjacent workstations & $\begin{array}{l}\text { Other work stations were positioned close to the induction } \\
\text { heater work station, exposing these workers to unnecessary } \\
\text { levels of magnetic fields that their work task did not require. } \\
\text { The latter could become more relevant with potential pregnant } \\
\text { workers at these work stations. }\end{array}$ \\
\hline 7 & $\begin{array}{l}\text { Lack of knowledge of } \\
\text { magnetic field }\end{array}$ & $\begin{array}{l}\text { The induction heater system's operator was unaware about the } \\
\text { field intensity from the heater and the propagation pattern of } \\
\text { the field from the heater. Also, other workers coming close to } \\
\text { the induction heating system were unaware about the magnetic } \\
\text { field. }\end{array}$ \\
\hline
\end{tabular}

The main intervention strategy is to increase the distance in between the induction heater set (heating coil and the control unit) and the worker. The worker approaches the heater work bench only when the unit is switched off: at the beginning while placing the raw product in the heating coil and at the end, while removing the heated unit from the coil. For that goal the heater control unit is equipped with an add-on technical solution - a remote control panel, connected to the main control unit via a cable. The remote control panel is placed to $3 \mathrm{~m}$ distance from the heater coil, which still allows reasonable operability and fast access to the system. The worker avoids any activities, including interacting with other workers or waiting for the end of the process in the vicinity of the active induction heater. The recommended intervention work procedure results in a significant decrease in the worker's exposure to the magnetic field: the accumulating dosage is only $5.2 \%$ and the timeweighted average exposure is $4.6 \%$ of the actual highest exposure scenario (table 2). Comparing the intervention scenario to the worst case nominal scenario revealed even greater difference, $0.9 \%$ and $0.8 \%$ respectively. 
Analysis of exposure to the magnetic field from working with an induction heater

\begin{tabular}{|c|c|c|c|c|}
\hline Statistics & $\begin{array}{c}\text { Duration of the } \\
\text { procedure (sec) }\end{array}$ & $\begin{array}{c}\text { Exposure time } \\
\text { during the } \\
\text { procedure (sec) }\end{array}$ & $\begin{array}{c}\text { Accumulating } \\
\text { dosage }(\boldsymbol{\mu} \text { T-sec) }\end{array}$ & $\begin{array}{c}\text { Time weighted } \\
\text { average-TWA } \\
\text { exposure }(\boldsymbol{\mu} \text { T) }\end{array}$ \\
\hline $\begin{array}{c}\text { Maximum of } \\
\text { exposimeter recorded } \\
\text { procedures }(N=5)\end{array}$ & 137 & 74 & 310 & 2.26 \\
\hline $\begin{array}{c}\text { Average of } \\
\text { exposimeter recorded } \\
\text { procedures }(N=5)\end{array}$ & 129 & 74 & 214 & 1.64 \\
\hline $\begin{array}{c}\text { Maximum of observed } \\
\text { procedures }(N=5)\end{array}$ & 127 & NA & 296 & 2.57 \\
\hline $\begin{array}{c}\text { Average of observed } \\
\text { procedures }(N=5)\end{array}$ & 121 & 74 & 248 & 2.01 \\
\hline $\begin{array}{c}\text { Nominal procedure } \\
\text { (worst case scenario) }\end{array}$ & 118 & $74^{1}$ & 1805 & 0.12 \\
\hline $\begin{array}{c}\text { Recommended } \\
\text { procedure (minimal } \\
\text { exposure scenario) }\end{array}$ & 130 & NA & 15 & \\
\hline
\end{tabular}

${ }^{1}$ The exposure time during one procedure interval is the same as statistically established time for an average procedure - this is the time taken by the field to heat the unit to a target temperature and for melting to occur. The exposure time characterizes the period while the induction heater is active, hence generating the magnetic field.

${ }^{N A}$ Data not available.

Figure 6 pictures the worker's actual exposure to the magnetic field from the induction heating system, based on the worker wearing a logging exposimeter. Each procedure round started with the blank unit preparation phase, which took the worker $14 \mathrm{sec}$ in average, followed by a heating phase. After the heater was automatically switched off, the worker conducted a press treatment of the unit and then retired the unit to the finished units tray, which took $35 \mathrm{sec}$ in average. In each round the activation of the induction heater is clearly identifiable by an abrupt rise in the exposure level, briefly after starting the procedure. While the unit was being heated by the magnetic field induction, the worker waited or dealt with secondary activities. Therefore, the exposure dynamics of the magnetic field generated by the induction system is different in all procedure rounds, due to the whereabouts of the worker. In two occasions the exposimeter limit of $20 \mu \mathrm{T}$ was reached, indicating a field above that level; but the log shows the incidents being very brief.

The difference in between the spatial measurements obtained and exposimeter registered exposure indicators is due to the location of the exposimeter, as the human body intersection width of approximately $0.4 \mathrm{~m}$ could position the exposimeter further away from the magnetic field source than where the rest of the body's perimeter is located. Also the varying amplitude of the magnetic field during the heating process plays a role, as the spatial grid measurements were taken mostly at the time of peak power, whereas the exposimeter logs the magnetic field level of corresponding amplitude at that moment.

Measurements done by Floderus et al. also concluded that spot measurements at the induction heater units were higher than those recorded by the worker held logging system, except for the brazing machine [15].

The exposimeter based frequency measurements identified the induction heater system to be the main exposure contributor at the frequency band of $2-400 \mathrm{kHz}$ (table 3). Somewhat amplitude was registered also at $50 \mathrm{~Hz}$ (mains power) frequency, but the exposure was negligent for an industrial setting. Due to the on and off switching of the induction heater system, there is a great variation in the amplitude of the magnetic field the operator is exposed to due course of the monitoring session. The amplitude variation could also be accounted by the operator moving around at the work area and being closer or further away from the induction heater system. 


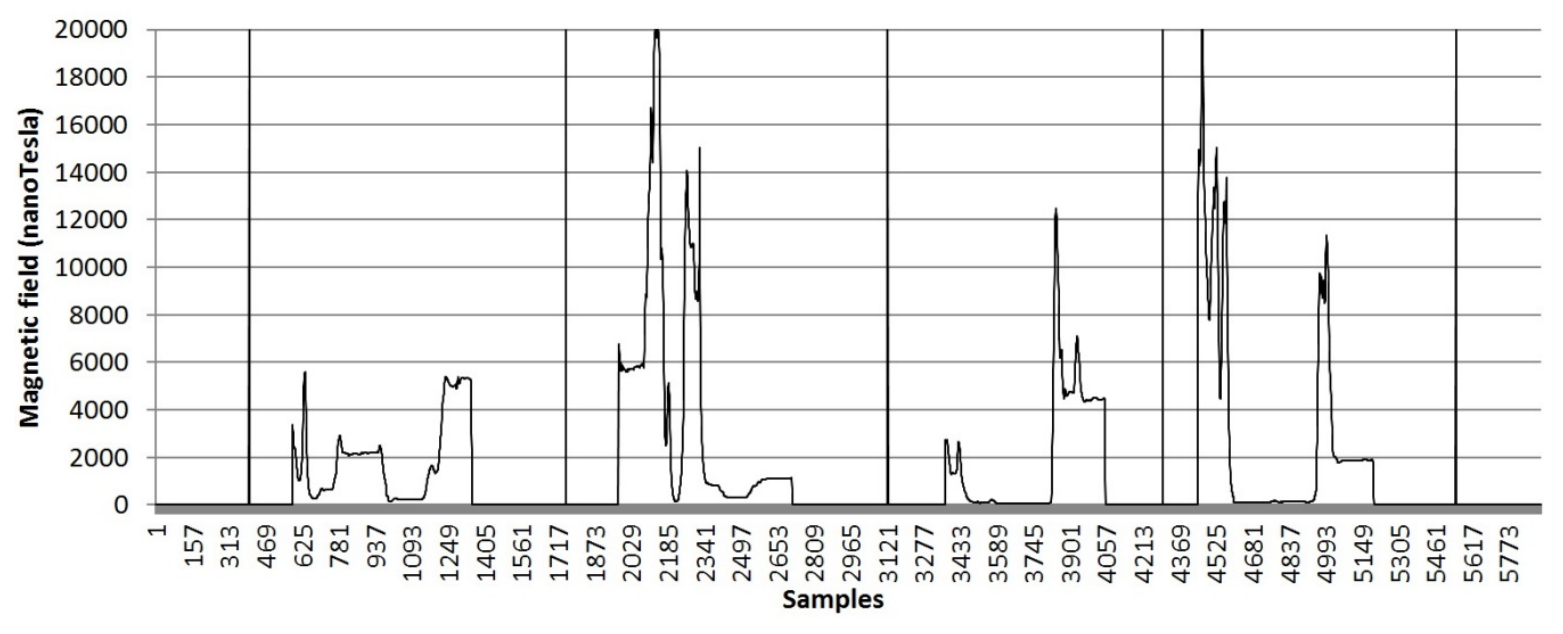

Fig. 6. Worker's exposure to the magnetic field from the induction heating system; an exposimeter excerpt of four consecutive procedure rounds - vertical bars mark the end/start of the procedure; horizontal bar represents samples taken (10 samples per sec)

Table 3

Frequency analysis of exposure to the magnetic field from working with an induction heater (in nanoTeslas - nT)

\begin{tabular}{|l|l|l|l|l|l|l|}
\hline Frequency & Mean & Median & Min & Max & 1. quartile & 3. quartile \\
\hline $50 \mathrm{~Hz}$ & 229 & 182 & 16.4 & 3208 & 64.8 & 314 \\
\hline $150 \mathrm{~Hz}$ & 15.2 & 13.8 & 0.5 & 73.7 & 12.8 & 16.2 \\
\hline$<2 \mathrm{kHz}$ & 16.8 & 6.5 & 0 & 95.7 & 2.8 & 30.1 \\
\hline$>2 \mathrm{kHz}$ & 1659 & 111 & 0 & 20974 & 0 & 1862 \\
\hline Total & 1796 & 351 & 19.9 & 20976 & 211 & 1867 \\
\hline
\end{tabular}

The spectrum measurements identified the operating frequency of the induction heater to be $12.5 \mathrm{kHz}$ (Figure 7), it was also identified that the harmonics extended up to $400 \mathrm{kHz}$.

For $12.5 \mathrm{kHz}$ the occupational exposure low and high action level for magnetic field is $100 \mu \mathrm{T}$ [2; 3]. The public exposure limit value for the same frequency is $6.25 \mu \mathrm{T}$ [16;17]. It should be emphasized that in case of safety of workers in risk groups the public limits should be followed. Also the public limits become relevant when third parties, e.g., the visitors visit the work area.

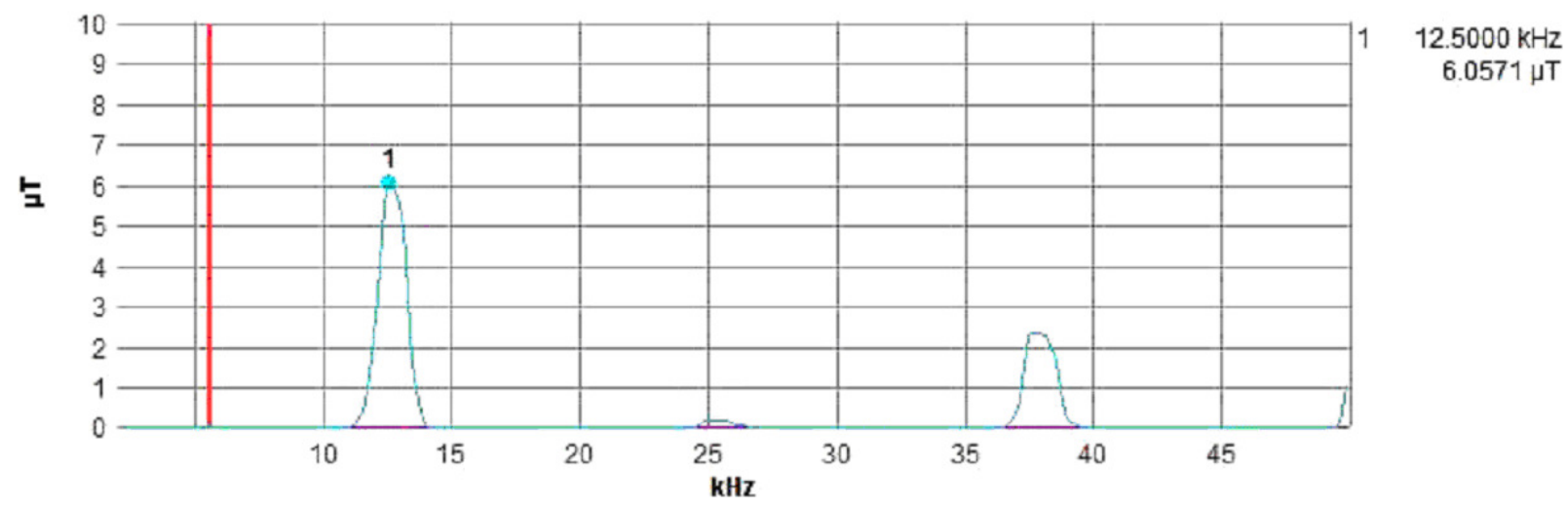

Fig. 7. Spectrometer excerpt of the frequency distribution of the induction heater, registered $0.6 \mathrm{~m}$ from the induction heater coil at $0.7 \mathrm{~m}$ height

The magnetic field level from the induction heater coil, as recorded by spectrum measurements at the fixed position of $0.6 \mathrm{~m}$ from the induction coil, shows abrupt change in the magnetic field when the unit is switched on/off and slight increase in the magnetic field level during the heating process (Figure 8).

The electric field component at the workplace was relatively low, $3-7 \mathrm{~V} \cdot \mathrm{m}^{-1}$ at the frequency band of the induction heater system $(2-400 \mathrm{kHz})$ at the worker's position. 


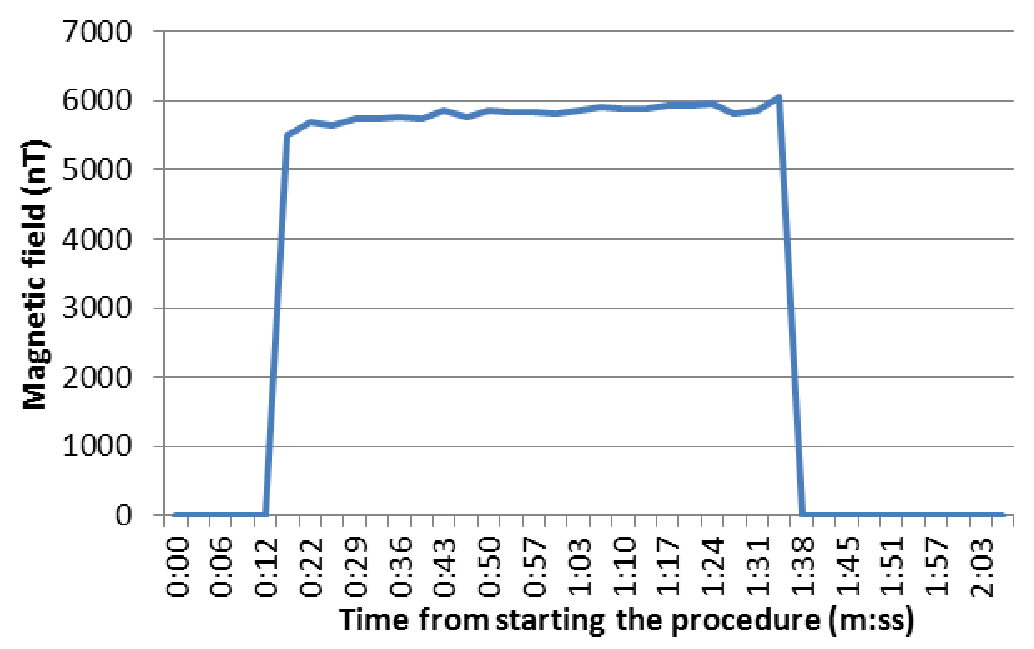

Fig. 8. Magnetic field level during one heating procedure at the induction heater operating frequency, registered $0.6 \mathrm{~m}$ from the induction heater coil at $0.7 \mathrm{~m}$ height

\section{Results and conclusions}

Visual observations and questionings of workers and their supervisors allowed developing the strategy for managing risks related to the magnetic field from the induction heater system. Technically, the worker is not required to be present, i.e. in close proximity to the induction heater while it is active.

Based on the new legislation on occupational exposure to the electromagnetic fields, the employer is tasked with detailed obligations on worker's safety. In assessing the workers' exposure not only the amplitude and the frequency of the electromagnetic field should be accounted, but special attention needs to be paid also to 1) the duration of the exposure, and 2) the type of exposure, including the distribution over the worker's body and over the volume of the workplace.

The employer is obligated to assess if any alternative technology could reduce the exposure, including technical modifications to the existing equipment or replacement equipment. The employer is also obligated to take into account technical progress and the availability of various measures to control the production of electromagnetic fields at the source and to take actions to reduce the fields.

Special attention needs to be paid to the safety of workers at particular risk (risk groups). These include workers with passive or active medical implant, pregnant workers and adolescents.

All the risk assessment questions should be viewed from the point of view, if the current exposure is really unavoidable, so that the work could not be completed in any other way.

It should be emphasized that the nominal working procedure developed for the heating process using the induction heater exposes the worker to unnecessary levels of the electromagnetic field. The circumstances of the exposure and the work procedure however grant several possibilities for reducing the exposure.

In reducing the workers exposure at the induction heaters work area the employer could undertake mainly technical and organizational safety measures. In Table 4 the safety measures prescribed by the legislation are analyzed in the framework of the current investigation and recommendations are presented. Based on the data gathered at the work area, shortcomings, which prescribe the high exposure of the worker, were identified. Work procedures were analyzed and alternative solutions developed to reduce workers exposure (Table 4). The recommendations were developed based on the new requirements for the occupational safety from the exposure to the electromagnetic fields: the directive 2013/35/EU [3] and the corresponding Estonian national legislation from 1.04.2016 [2].

In considering the sources of the magnetic field, 1) the induction heater coil, 2) cables carrying the current and 3) the current generator control unit, the placement of the equipment should account all of these in creating distance in between the worker and the system. Using alternative technology to reduce worker's exposure could include remote switches, which would not require the worker to be close to the current generating control unit, which is also the source of the magnetic field. The worker 
does not need to be in the vicinity of the control unit, the task of the worker is to set the right parameters for the heating process and press the button to activate the system - this could also be done from the distance using the remote control.

Table 4

Solutions to reduce the workers exposure to the magnetic field from the induction heater

\begin{tabular}{|c|c|c|}
\hline $\mathbf{N r}$ & $\begin{array}{l}\text { Safety measures } \\
\text { prescribed by the } \\
\text { relevant legislation }\end{array}$ & $\begin{array}{c}\text { Accustomed solutions to reduce exposure at the investigated } \\
\text { induction heater workplace }\end{array}$ \\
\hline a. & $\begin{array}{l}\text { Other working } \\
\text { methods that entail } \\
\text { less exposure to } \\
\text { EMFs }\end{array}$ & $\begin{array}{l}\text { The workers should minimize or completely avoid staying in the } \\
\text { vicinity of the MF source. The employer should rearrange work } \\
\text { procedures so that the worker does not need to go near the heater, } \\
\text { while it is active. The worker should only approach the heater when } \\
\text { the unit is switched off. The same principle applies also to the } \\
\text { arrangement of work of other workers not attached to this } \\
\text { workstation, e.g., workers delivering parts. }\end{array}$ \\
\hline b. & $\begin{array}{l}\text { Equipment emitting } \\
\text { less intense } \\
\text { electromagnetic } \\
\text { fields, taking account } \\
\text { of the work to be } \\
\text { done }\end{array}$ & $\begin{array}{l}\text { Since the induction heater system uses the magnetic field to heat up } \\
\text { metal, the propagation of the magnetic field might be considered } \\
\text { inevitable. Therefore, the choice of alternative models to do the } \\
\text { same job would not allow significant reduction in the propagated } \\
\text { magnetic field, unless these models are accompanied by the } \\
\text { shielding solutions. } \\
\text { The heating of the units and melting aluminum may be achieved } \\
\text { also by other heating technologies, but for certain products } \\
\text { induction heating might be the only option. }\end{array}$ \\
\hline c. & $\begin{array}{l}\text { Technical measures } \\
\text { to reduce the } \\
\text { emission of EMFs } \\
\text { including interlocks, } \\
\text { shielding etc. }\end{array}$ & $\begin{array}{l}\text { A control panel should be positioned separately from the main } \\
\text { system, so not to expose the worker while operating the system, } \\
\text { e.g., pressing the start button from the distance. } \\
\text { An option would be to apply a shield around the induction heater } \\
\text { coil. }\end{array}$ \\
\hline d. & $\begin{array}{l}\text { Delimitation and } \\
\text { access measures to } \\
\text { limit or control } \\
\text { access }\end{array}$ & $\begin{array}{l}\text { Zoning principles should be followed by marking lines on the floor } \\
\text { and equipment, indicating both occupational and public safety limits } \\
\text { at levels of, e.g., } 100 \%, 50 \% \text { and } 10 \% \text {. Workers, whose tasks are } \\
\text { not related to induction ovens, should be delimited from accessing } \\
\text { the high exposure area. }\end{array}$ \\
\hline e. & $\begin{array}{l}\text { Measures to manage } \\
\text { spark discharges and } \\
\text { contact currents }\end{array}$ & Applicable mainly to electric fields. \\
\hline f. & $\begin{array}{l}\text { Maintenance } \\
\text { programs }\end{array}$ & $\begin{array}{l}\text { The employer should organize regular maintenance of the induction } \\
\text { heater to ensure that malfunction or unauthorized readjustment of } \\
\text { the induction heater system would not expose workers to elevated } \\
\text { levels of magnetic fields. Also adjustments and maintenance } \\
\text { procedures should not be allowed while the heater is active. }\end{array}$ \\
\hline g. & $\begin{array}{l}\text { The design and } \\
\text { layout of workplaces } \\
\text { and workstations }\end{array}$ & $\begin{array}{l}\text { Having the control unit close to the heater also prescribes a } \\
\text { significant exposure level. Rearrangement of work equipment } \\
\text { including repositioning the control unit away from the heater } \\
\text { (recommended } 5 \text { meters) would decrease the worker's exposure. } \\
\text { Blank units and processed units trays should be positioned to the } \\
\text { work area considering that there is no exposure from the heater } \\
\text { system while the work with blank/ready unit is needed to be } \\
\text { fetched. Other work stations should be positioned away from the } \\
\text { induction heater system, since exposing these workers is } \\
\text { unnecessary. }\end{array}$ \\
\hline
\end{tabular}


Table 4 (continued)

\begin{tabular}{|c|l|l|}
\hline Nr & $\begin{array}{l}\text { Safety measures } \\
\text { prescribed by the } \\
\text { relevant legislation }\end{array}$ & \multicolumn{1}{|c|}{$\begin{array}{c}\text { Accustomed solutions to reduce exposure at the investigated } \\
\text { induction heater workplace }\end{array}$} \\
\hline h. & $\begin{array}{l}\text { Limitations of the } \\
\text { duration and } \\
\text { intensity of the } \\
\text { exposure }\end{array}$ & See point a. \\
\hline i. & $\begin{array}{l}\text { Personal protection } \\
\text { equipment }\end{array}$ & $\begin{array}{l}\text { Due to the physical propagation of the magnetic fields (toroidal } \\
\text { field lines) there is no practical personal protective equipment } \\
\text { suitable for the investigated case. However, metal parts on the body } \\
\text { and in garments should be avoided, as these tend to focus the field, } \\
\text { hence increasing the worker's exposure. }\end{array}$ \\
\hline j & Training of workers & $\begin{array}{l}\text { The workers should be trained especially in regard where high field } \\
\text { intensities are present, so they could avoid high exposure spots (e.g., } \\
\text { avoiding present scenarios where the worker just waits next to the } \\
\text { heater for the heating process to end). }\end{array}$ \\
\hline
\end{tabular}

The rearrangement of the devices, whereas the control unit is placed further away from the induction heater system and the workers are positioned further away from the magnetic field generating components, would inevitably add distance to the length of the path the worker needs to take to perform each single procedure. The extra time needed to undergo that extra distance is assessed to have relatively little impact on the total procedure time of about 2 min. Only approximately $10 \mathrm{sec}$ would be added to the length of the procedure. Also the placement of the equipment should consider the time when the induction system is actually active, i.e. approaching the induction heater bench would not accompany any exposure when the system is inactive. Therefore, it is reasonable to satisfy with the current setting where the blank units tray is positioned in near proximity of the induction heater coil at a distance of $\sim 1 \mathrm{~m}$. The same principle applies for the finished units tray and the postheat processing procedure at the press bench.

It was noted that in several occasions other workers came into the work area of the induction heater system and therefore were also exposed to the high magnetic field. These workers were delivering or retrieving the parts, signing documents, collaborating on work related issues etc. The high exposure of secondary workers could be avoided by moving these activities to outside of the active induction heater system work area. Also, the investigation unveiled the importance of schooling also other workers in the production, as they had no awareness of where and when the strong magnetic fields occur, nor of their risks to their health and safety.

Shielding is an option to be considered in mitigating the exposure to the magnetic field from the induction heater. Both passive and active shielding could be applied. Active shields generate counter fields that cancel or reduce the original field. A set of coils is included in the active shield, positioned in a way to account for the original field, the coils are driven by a control system, that follows the original field by magnetic sensors [18; 19].

In case the passive shield is used, this shield should not be close to the coil, since it would also be heated up. Also, since energy is lost in heating the shield, it would take more time to heat the processed unit. Limited shielding may be offered by one side screens that reduce the magnetic field at the side where the worker is waiting or where other workers are present. However, due to the physical propagation of the magnetic field (toroid field lines), one-sided screens offer comparatively less protection than full envelope shields.

Safety improvements would also include zoning principles, i.e. markings (lines) on the floor for 1) occupational exposure action levels and 2) public safety limits. The line should not be drawn only at $100 \%$ of the corresponding limit, but also $50 \%$ and $10 \%$ line could be considered as to make personnel aware of the risk agent.

Technical measures could also include signalling lamps and sounds, which warn the operator and other personnel when the unit is active: this would allow the personnel to keep proper distance to the 
source when needed, whereas in other times delivering or fetching parts may be needed to very close proximity of the induction heater system.

Appropriate signs should be attached to the working area including at the immediate work station and also at the entrance to the area. The latter should also be complemented by the instruction sheets for low risk work practices. The above mentioned risk mitigation measures would allow the workers or visitors to be informed of the relevant safety measures.

Training should focus on making workers aware where strong electromagnetic fields are present. The workers should know what the possible health effects from the exposure to these fields are and how to detect them. Indirect effects of the EMFs should also be covered by the EMF training program. Emphasis should be put on how workers could protect themselves, by example adapting new safe work practices. Training workers is also important due to their possible affiliation to the risk group. The safety of workers within the risk groups may be jeopardized, if they get too close to the induction heater system. The latter principle requires careful attention as workers sometimes do not report themselves being attached to the risk groups, e.g., the person carrying active or passive medical implant may be unaware of all the risks associated with their implants. Also, sometimes the workers are unaware that they belong to the risk group, e.g., women not yet knowledgeable about their pregnancy. Therefore, women within their childbearing age, especially the ones who plan to have children, should be encompassed into the training program. Possible damage to the development of the fetus would be most crucial to avoid at the beginning of pregnancy.

The average exposimeter measured exposure level $(1.65 \mu \mathrm{T})$ was in the same order of magnitude $(0.2-1.2 \mu \mathrm{T})$ as measured at induction heater workstations by Floderus. Their spot measurements at 0.5 $\mathrm{m}$ from the induction heater varied $0.4-20.9 \mu \mathrm{T}$ as compared to $20 \mu \mathrm{T}$ in the current induction heater work station [15].

The measurements and exposure assessment have demonstrated that the worker's exposure to the magnetic field from the induction heating unit is episodic and subject to large variations of amplitude during the heating procedure. The variation is due to the ON/OFF switching of the heating system and due to worker changing position at the work station. This results in short time exposure to relatively strong fields, when the worker has moved closer to the induction heater coil, as reported also in the literature $[9 ; 14 ; 20]$.

The results show that exposure during the induction heating procedure could be significantly reduced by implementing relatively easy mitigation measures, including workplace rearrangement, work procedures redesign etc. Time-weighted average exposure to the magnetic field could be lowered from $2.57 \mu \mathrm{T}$ (maximum observed procedure) to $0.12 \mu \mathrm{T}$ (recommended procedure after interventions). The investigation also revealed that at present little attention is paid to training the workers who may be affected by high levels of EMFs. Considering the requirements of the new EMF legislation, immediate planning of appropriate schooling programs is necessary for all parties involved: employers, workers, work environment specialists.

\section{References}

1. Meredith R.J. Engineers' handbook of industrial microwave heating, IEE Power., no. 25. London: The Institution of Electrical Engineers, 1998.

2. Vabariigi Valitsuse määrus 01.04.2016 nr 44, “Töötervishoiu ja tööohutuse nõuded elektromagnetväljadest mõjutatud töökeskkonnale, elektromagnetväljadega kokkupuute piirnormid ja rakendusväärtused ning elektromagnetväljade mõõtmise kord,” Riigi Teat., vol. RT I, 07.0, no. 4, 2016. (In Estonian)

3. The European Parliament and the Council, Directive 2013/35/EU on the minimum health and safety requirements regarding the exposure of workers to the risks arising from physical agents (electromagnetic fields), vol. Official J, no. June. 2013, p. L 179/1-21.

4. Osepchuk J.M. "A History of Microwave Heating Applications," IEEE Trans. Microw. Theory Tech., vol. 32, no. 9, 1984, pp. 1200-1224.

5. White W. "Early History of Industrial Electronics," Proc. IRE, vol. 50, no. 5, 1962 pp. 1129-1135.

6. Stuchly M.A., Lecuyer D.W. "Induction Heating and Operator Exposure to Electromagnetic Fields.," Health Phys., vol. 49, no. 5, 1985. 
7. Mild K.H., Lovstrand K.G. "Biological Effects and Medical Applications of Electromagnetic Energy," O. P. Gandhi, Ed. Englewood Cliffs, New Jersey: Prentice Hall, 1990, pp. 48-74.

8. Mantiply E.D., Pohl K.R., Poppell S.W., Murphy J.A. "Summary of measured radiofrequency electric and magnetic fields (10 kHz to $30 \mathrm{GHz})$ in the general and work environment.," Bioelectromagnetics, vol. 18, no. 8, 1997, pp. 563-77.

9. Decat G., Deckx L., Meynen G., De Graef E., Jonlet F. "Magnetic Fields of Induction Heaters in the Framework of Directive 2004/40/EC of the European Parliament and of the Council," Int. J. Occup. Saf. Ergon., vol. 12, no. 2, 2006, pp. 169-176.

10. Conover D.L., Murray W.E., Lary J.M., Johnson P.H. "Magnetic field measurements near RF induction heaters," Bioelectromagnetics, vol. 7, no. 1, 1986, pp. 83-90.

11. Rudnev V., Loveless D., Cook R.L., Black M. Handbook of induction heating. CRC Press, 2002.

12. Lucia O., Maussion P., Dede E.J., Burdio J.M "Induction Heating Technology and Its Applications: Past Developments, Current Technology, and Future Challenges," IEEE Trans. Ind. Electron., vol. 61, no. 5, May 2014, pp. 2509-2520.

13. Runde M., Magnusson N., Fülbier C., Bührer C. "Commercial induction heaters with hightemperature superconductor coils," IEEE Trans. Appl. Supercond., vol. 21, no. 3 PART 2, 2011, pp. 1379-1383.

14. World Health Organization., International Agency for Research on Cancer., and F. IARC Working Group on the Evaluation of Carcinogenic Risks to Humans (2001: Lyon, IARC Monographs on the evaluation of carcinogenic risks to humans, Vol 80, Non-ionizing radiation, part1: Static and extremely low-frequency (ELF) electric and magnetic fields. IARC Press, 2002.

15. Floderus B., Stenlund C., Carlgren F. "Occupational Exposures to High Frequency Electromagnetic Fields in the Intermediate Range (>300 Hz-10 MHz)," Bioelectromagnetics, vol. 23 , no. 8, 2002, pp. 568-577.

16. Sotsiaalministri määrus nr 38. 21.02.2002, Mitteioniseeriva kiirguse piirväärtused elu- ja puhkealal, elamutes ning ühiskasutusega hoonetes, õpperuumides ja mitteioniseeriva kiirguse tasemete mõõtmine, vol. 40, no. 563. 2002, pp. 1-8.

17. The Council of the European Communities, "Council Recommendation of 12 July 1999 on the limitation of exposure of the general public to electromagnetic fields $(0 \mathrm{~Hz}$ to $300 \mathrm{GHz})$," Off. J. Eur. Communities, vol. L199, 1999, pp. 59-70.

18. Antonini G., Cristina S. "An efficient digital controller for active shielding circuits," in Electromagnetic Compatibility, 2000. IEEE International Symposium on, 2000, vol. 1, pp. 49-53.

19. Sergeant P., Dupré L., Melkebeek J., Vandenbossche L. "Magnetic field computation for optimized shielding of induction heaters," J. Comput. Appl. Math., vol. 168, no. 1, 2004, pp. 437-446,

20. NRPB - National Radiological Protection Board (UK), ELF electromagnetic fields and the risk of cancer, Report of an Advisory Group on Non-ionising Radiation, Doc NRPB 1. Chilton, 2001. 